\title{
Efficiency and Cost Analysis of Cell Saver Auto Transfusion System in Total Knee Arthroplasty
}

\author{
Mustafa Gökhan Bilgili ${ }^{1}$, Ersin Erçin ${ }^{1}$, Gökhan Peker $^{2}$, Cemal Kural $^{1}$, Serdar Hakan Başaran ${ }^{3}$, \\ Altuğ Duramaz ${ }^{1}$, Cevdet Avkan ${ }^{1}$ \\ ${ }^{1}$ Department of Orthopedics and Traumatology, Bakırköy Dr. Sadi Konuk Research and Training Hospital, İstanbul, Turkey \\ ${ }^{2}$ Department of Orthopedics and Traumatology, Trabzon Kanuni Research and Training Hospital, Trabzon, Turkey \\ ${ }^{3}$ Department of Orthopedics and Traumatology, Karabük University Faculty of Medicine, Zonguldak, Turkey
}

\begin{abstract}
Background: Blood loss and replacement is still a controversial issue in major orthopaedic surgery. Allogenic blood transfusion may cause legal problems and concerns regarding the transmission of transfusion-related diseases. Cellsaver Systems (CSS) were developed as an alternative to allogenic transfusion but CSS transfusion may cause coagulation, infection and haemodynamic instability.

Aims: Our aim was to analyse the efficiency and cost analysis of a cell saver auto-transfusion system in the total knee arthroplasty procedure.

Study Design: Retrospective comparative study.

Methods: Those patients who were operated on by unilateral, cemented total knee arthroplasty (TKA) were retrospectively evaluated. Group 1 included 37 patients who were treated using the cell saver system, and Group 2 involved 39 patients who were treated by allogenic blood transfusion. The groups were compared in terms of preoperative haemoglobin and haematocrit levels, blood loss and transfusion amount, whether allogenic transfusion was made, degree of deformity, body mass index and cost.
\end{abstract}

Results: No significant results could be obtained in the statistical comparisons made in terms of the demographic properties, deformity properties, preoperative laboratory values, transfusion amount and length of hospital stay of the groups. Average blood loss was calculated to be less in Group $1(\mathrm{p}<0.05)$ and cost was higher in Group 1 $(\mathrm{p}<0.05)$.

Conclusion: Cell saver systems do not decrease the amount of allogenic blood transfusion and costs more. Therefore, the routine usage of the auto-transfusion systems is a controversial issue. Cell saver system usage does not affect allogenic blood transfusion incidence or allogenic blood transfusion volume. It was found that preoperative haemoglobin and body mass index rates may affect allogenic blood transfusion. Therefore, it is foreseen that auto-transfusion systems could be useful in patients with low haemoglobin level and body mass index.

(Balkan Med J 2014;31:149-53).

Key Words: Cell saver system, cost, total knee arthroplasty
Blood loss and replacement during surgery is a controversial issue in major orthopaedic surgery such as Total Knee Arthroplasty (TKA). Allogeneic blood transfusion causes legal problems and concerns in terms of transmission of transfusion-related diseases. Therefore, cell saver systems (CSS) were developed to minimize the need for allogeneic blood transfusion. However, contradictory results have arisen from studies examining the use of CSS to reduce the need for allogeneic blood transfusion in primary TKA (1-3). Additionally, transfusion by CSS may also cause coagulation, infection and haemodynamic instability (4). The autologous blood should be used within 6 hours in order to prevent potential contamination and febrile reactions (5-7).

This study investigated the effect of CSS use on levels of allogeneic blood transfusion in TKA patients and the associ- ated costs. An attempt was also made to determine the factors predicting the need for allogeneic blood transfusion.

\section{MATERIAL AND METHOD}

Following approval from the Ethics Committee of our hospital and having informed consent by all patients, patients undergoing unilateral, cemented TKA for primary knee osteoarthritis between January 2012 and June 2013 in our clinic were retrospectively evaluated. In Group 1, 37 patients were treated with a CSS, and in Group 2, 39 patients were given allogeneic blood transfusion. Simultaneous bilateral TKA cases, revision surgery and missing medical record cases were excluded from the study. Patients who had inflammatory arthritis, haematological disease, post-operatively developing myocardial 
infarction, pulmonary embolism or gastrointestinal bleeding were also excluded.

A Medtronic autologous transfusion set (Minnesota, USA) was used in all cases. The preoperative demographic data of the patients such as age, height $(\mathrm{m})$, weight $(\mathrm{kg})$ and BMI $\left(\mathrm{kg} / \mathrm{m}^{2}\right)$ were recorded. The preoperative mechanical axis of the lower extremity in the anterior-posterior view in the standing position was measured by an orthopaedist who was not a member of the operating team (Table 1).

Low molecular weight heparin and deep venous thromboprophylaxis with antithromboembolic socks were used in all cases. Haemoglobin levels of 8 and lower were considered an absolute transfusion indication. Transfusion was also conducted in the presence of tachycardia and hypotension. The patients were closely monitored against autotransfusion or allogeneic blood transfusion-related adverse reactions for 7 to 10 days postoperatively.

$\mathrm{Hb}$ values on the first, second, third, fifth and seventh days; total blood volume accumulating in the drain; retransfusion level in CSS cases; and the allogeneic blood transfusion volume in each group were calculated and recorded. In the group in which CSS was not used, the amount of blood lost was calculated and recorded by measuring the blood drained from the negative pressure system.

Within the first 5 hours blood that was collected after the operation was given to the CSS group. Drain systems were active for 2-3 days postoperatively in both groups.

The groups were compared in terms of preoperative haemoglobin, amount of blood transfused (and whether allogeneic transfusion was essential), length of hospitalisation and cost.

\section{Surgical technique}

Two surgeons from our clinic operated on patients by applying a pneumatic tourniquet via an epidural. The Zimmer® Gender Solutions ${ }^{\circledR}$ Nexgen ${ }^{\circledR}$ High-Flex Knee prosthesis, which cuts the posterior cruciate ligaments, was used in all 76 knees. Surgery was performed using the medial parapatellar approach. All implants were applied with cement and no patellar component was used in any patient. Negative pressure drainage was used while closing the wounds and an elasticated bandage was applied for compression after finishing the tourniquet.

\section{Statistical analysis}

Statistical analysis was conducted using SPSS version 12 (SPSS Inc., Chicago, IL, USA). Demographic data were compared using Student's $t$ test for continuous variables or the Chi-square test for categorical variables. ANOVA was used for repeated measurements in order to compare the serial changes between the preoperative and postoperative levels of $\mathrm{Hb}$. The Chi-square test was used to determine the relationship between the use of CSS and allogeneic blood transfusion. Pearson test correlation analysis was used to determine the relationship between re-transfusion and allogeneic blood transfusion and for cost analysis. The effect of demographic variables on the allogeneic blood transfusion was examined using multiple logistic regression analysis, which contained corrected variables, uncor- rected variables and inequality rates. Differences were considered significant at $\mathrm{p}<0.05$ in all tests.

\section{RESULTS}

Table 2 presents the comparison of postoperative data between groups. The two groups showed similarity in terms of the haemoglobin levels, which dropped on the first and seventh day postoperatively. The $\mathrm{Hb}$ level was lower than the preoperative level in the first 3 days, and then had a tendency to increase but stayed below the preoperative status. This tendency was similar in the two groups $(p=0.216)$.

The groups also showed similarity in terms of the total blood volume drained. The average total blood loss was 550 [50-675] $\mathrm{mL}$ in Group 1, and 770 [70-1100] mL; (p:0.045) in Group 2.

The average total allogeneic blood transfusion volume was similar in the two groups (Group 1: 165 [0-460] mL, Group 2: 255 [0-670] $\mathrm{mL} ; \mathrm{p}=0.321$ ).

The Chi-square test was used to determine the relationship between the use of allogeneic blood transfusion and CSS (Table 3). The use of CSS did not affect the incidence of allogeneic blood

TABLE 1. Preoperative demographic properties of patients

\begin{tabular}{lccc}
\hline & CSS & ABT & p value \\
\hline Age (year) & $64(57-73)$ & $66(56-75)$ & $>0.05$ \\
Gender (F/M) & $28 / 9$ & $31 / 8$ & \\
Weight $(\mathrm{kg})$ & $87.4(65-102)$ & $89.3(67-104)$ & $>0.05$ \\
Height $(\mathrm{cm})$ & $162(154-170)$ & $160(152-172)$ & $>0.05$ \\
BMI $\left(\mathrm{kg} / \mathrm{m}^{2}\right)$ & $28.4(22.2-32.6)$ & $28.7(22.6-33.2)$ & $>0.05$ \\
$\begin{array}{l}\text { Preoperative Hb value } \\
\text { g/dL) }\end{array}$ & $12.5(10.2-15.6)$ & $12.7(10.2-15.4)$ & $>0.05$ \\
$\begin{array}{l}\text { Mean value of preoperative } \\
\text { varus deformity (degree) }\end{array}$ & $9.8 \pm 6.4$ & $10.2 \pm 5.8$ & $>0.05$ \\
\hline $\begin{array}{l}\text { CSS: cell saver system; ABT: allogeneic blood transfusion; BMI: body mass index; Hb: } \\
\text { haemoglobin }\end{array}$ & & \\
Values represent mean \pm standard deviation (range) & &
\end{tabular}

TABLE 2. Postoperative transfusion amounts, $\mathrm{Hb}$ levels and amount of blood loss in each group

\begin{tabular}{lccc}
\hline & CSS & ABT & p value \\
\hline $\begin{array}{l}\text { Average blood loss (mL) } \\
\text { Allogeneic blood transfusion }\end{array}$ & $550(50-675)$ & $770(70-1100)$ & $<0.05$ \\
volume (mL) & & $225(0-670)$ & $>0.05$ \\
$\begin{array}{l}\text { Decrease in first postoperative } \\
\text { day Hb level (gm/dL) }\end{array}$ & $2.6(0.5-3.9)$ & $2.5(0.2-4.4)$ & $>0.05$ \\
$\begin{array}{l}\text { Decrease in 7 } 7^{\text {th }} \text { postoperative } \\
\text { day Hb level (gm/dL) }\end{array}$ & $2.2(0.8-4.9)$ & $2.3(0.7-5.4)$ & $>0.05$ \\
$\begin{array}{l}\text { Drained blood volume (mL) } \\
\text { Hospitalization period (days) }\end{array}$ & $655(110-1220)$ & $710(50-1440)$ & $>0.05$ \\
Cost (TL) & $300(0-600)$ & $110(0-400)$ & $<0.05$ \\
\hline
\end{tabular}

CSS: cell saver system; ABT: allogeneic blood transfusion; Hb: haemoglobin Values represent mean \pm standard deviation (range) 
TABLE 3. Relationship between use of CSS and use of ABT

\begin{tabular}{lccc}
\hline Variable & ABT $(+)$ & ABT $(-)$ & p value \\
\hline CSS group $(\mathrm{n}=37)$ & $9(24 \%)$ & $28(76 \%)$ & $>0.05$ \\
ABT group $(\mathrm{n}=39)$ & $15(38 \%)$ & $24(62 \%)$ & $>0.05$ \\
Total $(\mathrm{n}=76)$ & $24(31 \%)$ & $52(69 \%)$ & \\
\hline
\end{tabular}

CSS: cell saver system; ABT: allogeneic blood transfusion

The percentage in parentheses is the proportion of cases in each group

transfusion $(\mathrm{p}=0.45)$. Thirteen patients $(35 \%)$ in Group 1 and 19 patients (48\%) in Group 2 were given an allogeneic blood transfusion ( $\mathrm{p}=0.381$ ). In the group in which CSS was used, there was no correlation between the re-transfusion volume and the need for allogeneic blood transfusion ( $\mathrm{p}=0.116$ ).

Multiple regression analyses were conducted to determine the independent determinants of the use of allogeneic blood transfusion, which were also considered as dependent determinants. Age, BMI, preoperative deformity, $\mathrm{Hb}$, haematocrit and the use of CSS were included as potential independent variables. Single variable logistic regression analysis indicated that BMI, preoperative $\mathrm{Hb}$ and preoperative haematocrit variables affected the incidence of allogeneic blood transfusion. These variables were included in the multiple logistic regression analysis and the results indicated that preoperative $\mathrm{Hb}$ and $\mathrm{BMI}$ variables did not affect the use of allogeneic blood transfusion. While checking other variables, it was shown that one unit increase in BMI reduced the possibility of allogeneic blood transfusion by a factor of $0.95(\mathrm{p}=0.06)$ and a $1 \mathrm{~g} / \mathrm{dL}$ increase in preoperative $\mathrm{Hb}$ concentration reduced the possibility of allogeneic blood transfusion by a factor of 0.482 (p:0.02). Therefore, high BMI or high preoperative $\mathrm{Hb}$ values were found to be related to a reduction in the incidence of allogeneic blood transfusion. In contrast, the use of allogeneic blood transfusion was not affected by age, total blood loss, degree of preoperative malalignment or the use of CSS.

The Pearson test was used to conduct the cost analysis in two different ways: evaluating the relation in re-transfusion and the relation in allogeneic blood transfusion. The average cost was 300 TL in Group 1 and 110 TL in Group 2 These results were assessed as significant in statistical comparison $(\mathrm{p}=0.01)$.

Three patients complained of shivering in Group 1 and one patient had vomiting and chest pain following autotransfusion. These side effects declined after the transfusion ended. Before finishing transfusion the volume of transfused blood was recorded as the study value in these cases. Fever and nausea developed in four patients following allogeneic blood transfusion. The transfusion volume in these patients was recorded as the study value before complaints arose.

\section{DISCUSSION}

Autologous blood transfusion systems reduce the risk of infection arising after allogeneic blood transfusion but they may also cause coagulation, infection and hemodynamic instability (4). Although the use of CSS can reduce the need for allogeneic blood transfusion, contradictory results have been reported (4). In their randomized, controlled study, Kirkos et al. (8) reported that the haemoglobin values of the group given autologous transfusion were higher in the $8^{\text {th }}$ and $24^{\text {th }}$ hours and that less allogeneic transfusion was required. In a retrospective study conducted by Moonen et al. (9) it was shown that only $5.1 \%$ of the TKA patients needed allogeneic blood transfusion and the authors concluded that autotransfusion plays an important role in arthroplasty. In another prospective randomized clinical study conducted by Moonen et al. (10), the allogeneic blood transfusion rate in TKA patients who were given autotransfusion was lower when compared to those who were not. This indicates that cell saver systems are an effective and reliable method that reduces the need for allogeneic transfusion in primary TKA. However, other studies have reported contradictory results. Martin and von Strempel (11) found that re-transfusion of the blood collected from wound drains did not reduce the need for homologue blood transfusion. In their study, the allogeneic blood transfusion rate was lower in the group in which CSS was not used when compared to the group in which CSS was used. In another prospective randomized controlled study, the need for allogeneic blood transfusion was similar in patients who used and who did not use CSS (12). Likewise, in a prospective study by Glynn et al. (13) it was concluded that the postoperative use of CSS did not affect the incidence of allogeneic blood transfusion. Likewise, the allogeneic blood transfusion rates in patients who used and who did not use CSS were similar in this study.

The contradiction between the findings obtained for CSS users can be explained as follows. The preoperative haemoglobin levels differed between studies. The inclusion of patients with high haemoglobin values reduced the need for blood transfusion in the postoperative period. Moonen et al. (9) stated that the lack of relationship between allogeneic blood transfusion and re-transfusion did not originate from the tamponade-creating effect of haematoma that occurs postoperatively. This is probably because haematoma increases the blood volume of CSS drained due to vacuum.

In our study, the preoperative factors that stipulated the need for allogeneic blood transfusion were the $\mathrm{Hb}$ and BMI levels. The effect of preoperative $\mathrm{Hb}$ on allogeneic blood transfusion has been shown in many studies $(4,14)$. In some studies, preoperative $\mathrm{Hb}$ was the only factor that predicted the use of allogeneic blood transfusion (14). Jain and Jain reported that a lower preoperative $\mathrm{Hb}$ level is related to an increased need for allogeneic blood transfusion (15). In a prospective study that audited primary TKA cases, patients with lower preoperative $\mathrm{Hb}$ levels required more allogeneic blood transfusion (13).

On the other hand, opposing results have been reported by other studies. In their prospective empirical study, Strmper et al. (16) 
stated that there were no differences between the $\mathrm{Hb}$ concentrations of patients who did or did not receive allogeneic blood transfusion. On the other hand, in terms of BMI, there was no correlation with blood loss in which allogeneic blood transfusion during TKA was not examined in that study (17).

The use of re-transfused blood has a risk of complications (18). Handel et al. (19) reported that febrile reaction was seen during autotransfusion in 3 of 81 patients. This was associated with an increased IL-6 level in the blood drained in the early postoperative period. Carless et al. (20) argued that autotransfusion should be applied carefully due to problems such as air emboli, infection, nephrotoxicity, metabolic hyperchloremic acidosis and disseminated intravascular coagulation. In the current study, two CSS patients reported shivering following re-transfusion and this was solved by ending re-transfusion.

The limitations of our study are the small size of our study groups and the implementation of retrospective examination. The average allogeneic blood transfusion rate in our study was $24 \%$ in Group 1. This value is high when compared with previously published studies $(9,10)$. We associate this with the fact that the average preoperative haemoglobin values were low in our study. The preoperative BMI values of the patients in the study were lower than the BMI values in other studies (4). This may also explain the high transfusion rate in our study. In addition to preoperative haemoglobin, we believe that low BMI may be a determining factor in the need for allogeneic blood transfusion. Our study covers the predetermined involving and non-involving criteria and we also made an effort to rationalize the data collection process.

In terms of cost analysis, the cost effectiveness of CSS was negative in TKA. This was consistent with the literature (21, 22). However, CSS should always be considered particularly for patients having a low preoperative haemoglobin level and patients who experienced side effects in previous blood transfusions.

In conclusion, in our study we found that the use of CSS did not reduce the need for allogeneic blood transfusion and was more expensive in terms of cost analysis. Therefore, we do not recommend the routine use of autotransfusion systems. The use of CSS did not affect the incidence of allogeneic blood transfusion nor the volume of allogeneic blood transfusion. We found that preoperative $\mathrm{Hb}$ and BMI levels influenced the use of allogeneic blood transfusion. Therefore, the use of autotransfusion systems may only be useful in TKA patients with low $\mathrm{Hb}$ and $\mathrm{BMI}$ levels.

Ethics Committee Approval: Ethics committee approval was received for this study from the ethics committee of BEAH Clinical Studies.

Informed Consent: Written informed consent was obtained from patients who participated in this study.

Peer-review: Externally peer-reviewed.
Author contributions: Concept - M.G.B., E.E., G.P.; Design - M.G.B., C.K.; Supervision - C.A., C.K.; Resource - S.H.B., A.D.; Materials - G.P., A.D.; Data Collection\&/or Processing - S.H.B., G.P., A.D.; Analysis\&/or Interpretation - M.G.B., E.E., C.K., C.A.; Literature Search - M.G.B., S.H.B., E.E.; Writing - M.G.B., E.E., C.A.; Critical Reviews -C.A., C.

Conflict of Interest: No conflict of interest was declared by the authors.

Financial Disclosure: The authors declared that this study has received no financial support.

\section{REFERENCES}

1. Cushner F, Lee G-C, Scuderi G, Arsht S, Scott WN. Blood loss management in high-risk patients undergoing total knee arthroplasty: a comparison of two techniques. J Knee Surg 2006;19:249-53. [CrossRef]

2. Rees JE, Jeavons R, Dixon JH. An economic justification for autologous blood re-infusion in primary total knee replacement surgery. Ann R Coll Surg Engl 2005;87:102-5. [CrossRef]

3. Sinclair K, Clarke H, Noble B. Blood management in total knee arthroplasty: a comparison of techniques. Orthopedics 2009;32:19. [CrossRef]

4. Lee DH, Padhy D, Lee SH, Kim TK, Choi J, Han SB. Shed blood re-transfusion provides no benefit in computer-assisted primary total knee arthroplasty. Knee Surg Sports Traumatol Arthrosc 2011;19:926-31. [CrossRef]

5. Moonen AFCM, Neal TD, Pilot P. Peri-operative blood management in elective orthopaedic surgery. A critical review of the literature. Injury 2006;37(Suppl 5):11-6. [CrossRef]

6. Murray DJ, Gress K, Weinstein SL. Coagulopathy after reinfusion of autologous scavenged red blood cells. Anesth Analg 1992;75:125-9. [CrossRef]

7. Kandel L, Vasili C, Kirsh G. Extramedullary femoral alignment instrumentation reduces blood loss after uncemented otal knee arthroplasty. $J$ Knee Surg 2006;19:256-8. [CrossRef]

8. Kirkos J, Krystallis C, Konstantinidis P, Papavasiliou K, Kyrkos M, Ikonomidis L. Postoperative re-perfusion of drained blood in patients undergoing total knee arthroplasty: is it effective and cost-efficient? Acta Orthop Belg 2006;72:18-23.

9. Moonen AFCM, Thomassen BJW, van Os JJ, Verburg AD, Pilot P. Retransfusion of filtered shed blood in everyday orthopaedic practice. Transfus Med 2008;18:355-9. [CrossRef]

10. Moonen AFCM, Knoors N, van Os J, Verburg A, Pilot P. Retransfusion of filtered shed blood in primary total hip and knee arthroplasty: a prospective randomized clinical trial. Transfusion 2007;47:379-84. [CrossRef]

11. Martin A, von Strempel A. Transfusion of autologous blood from reinfusion systems in total knee arthroplasty. Int Orthop 2006;30:541-544. [CrossRef]

12. Abuzakuk T, Kumar VS, Shenava Y, Bulstrode C, Skinner JA, Cannon SR, et al. Autotransfusion drains in total knee replacement. Are they alternatives to homologous transfusion? Int Orthop 2007;31:235-9. [CrossRef]

13. Glynn A, McCarthy T, McCarroll M, Murray P. A prospective audit of blood usage post primary total knee arthroplasty. Acta Orthop Belg 2006;72:24-8

14. Jones H, Savage L, White C, Goddard R, Lumley H, Kashif F, et al. Postoperative autologous blood salvage drains - are they useful in primary uncemented hip and knee arthroplasty? A prospective study of 186 cases. Acta Orthop Belg 2004;70:466-73.

15. Jain R, Jain S. Blood salvage in total hip and knee arthroplasty in a community hospital: a retrospective study. J Orthop Surg 2005;13:19-26.

16. Strmper D, Weber EWG, Gielen-Wijffels S, Van Drumpt R, Bulstra S, Slappendel R, Durieux ME, Marcus MAE. Clinical efficacy of postoperative autologous transfusion of filtered shed blood in hip and knee arthroplasty. Transfusion 2004;44:1567-71. [CrossRef] 
17. Prasad N, Padmanabhan V, Mullaji A. Blood loss in total knee arthroplasty: an analysis of risk factors. Int Orthop 2007;31:39-44. [CrossRef]

18. Southern EP, Huo MH, Mehta JR, Keggi KJ. Unwashed wound drainage blood. What are we giving our patients? Clin Orthop Relat Res 1995;320:235-46.

19. Handel M, Winkler J, Hrnlein RF, Northoff H, Heeg P, Teschner M, et al. Increased interleukin- 6 in collected drainage blood after total knee arthroplasty: an association with febrile reactions during retransfusion. Acta Orthop Scand 2001;72:270-2. [CrossRef]
20. Carless P, Moxey A, O’Connell D, Henry D. Autologous transfusion techniques: a systematic review of their efficacy. Transfus Med 2004;14:123-44. [CrossRef]

21. Attaran S, Mcllroy D, Fabri BM, Pullan MD. The use of cell salvage in routine cardiac surgery is ineffective and not cost-effective and should be reserved for selected cases. Interact Cardiovasc Thorac Surg 2011;12:824-6. [CrossRef]

22. Reitman CA, Watters WC 3rd, Sassard WR. The Cell Saver in adult lumbar fusion surgery: a cost-benefit outcomes study. Spine (Phila Pa 1976) 2005;29:1580-3. [CrossRef] 